\title{
Statistical Model of The Postcombustion Subprocess in an Oven of Multiple Hearth Furnace
}

\author{
Deynier Montero Góngora* \\ Moa University, Cuba \\ *Corresponding author: Deynier Montero Góngora, Moa University, Cuba
}

\begin{abstract}
Complex multivariable processes are generated in multi-hearth furnaces, and their modeling contains a high index of uncertainty. The main variables that characterize the post-combustion subprocess were identified and data were taken that comprise a period of three months of operation of the installation, to which a regression analysis was carried out step by step backwards. This analysis allowed us to determine that the linear correlation coefficient for hearth temperature four was 0.79 and 0.65 for hearth temperature six, in addition to identifying the independent variables that most influence these process output variables.
\end{abstract}

Keywords: Furnaces, Post-Combustion subprocess, Regression analysis

\section{Introduction}

Nickel-producing companies are characterized by continuous processes of great complexity; that require automation to achieve greater efficiency in their productions. The Company under study operates according to the carbonate-ammoniacal leaching scheme for reduced ore. This company has a multi-hearth reduction furnace plant, which constitutes a key stage in the production process. The reduction furnaces are large metal cylinders, where basically the reduction of nickel oxide and cobalt is carried out to their corresponding metallic forms [1]. In these equipments it is required to maintain a profile of temperature and reducing gases (carbon monoxide and hydrogen), for each hearth, its noncompliance produces significant losses due to the formation of crystalline structures of iron spinels, olivines and pyroxenes that trap nickel and to cobalt in the form of oxides and to a lesser extent in a metallic state, and to the appearance of high contents of metallic iron in the reduced mineral. This results in a decrease in nickel and cobalt extraction in the leaching process [2]. To contribute to the establishment of the thermal profile required by the furnace, secondary air is introduced into hearths four and six (post-combustion), with the purpose of guaranteeing the complete combustion of residual carbon monoxide and other combustible gases that come from incomplete combustion in lower hearths. In this exothermic reaction, an amount of heat is generated that contributes to the preheating and drying of the mineral. The control loop of hearth four operates automatically and in hearth six manually, as a consequence the chemical physical process that takes place in these hearths is not carried out efficiently; observing temperature oscillations, which affect the thermal and aerodynamic processes that take place in the furnace. The literature consulted shows linear mathematical models for the furnaces of a company with similar characteristics, which operated under different operating conditions [3]. These models were achieved through experimental identification, for mean square fit values between 0.72 and 6.1. Also defined as input variables: the air flow to hearths four and six, and as output variables: the temperature corresponding to these hearths. Montero [4], obtained dynamic mathematical models, with adjustment between 62 and $72 \%$, which characterize the reduction furnaces of the company in question; where they were selected as input variables: the flow of ore fed to the furnace; Air flow to hearths four and six. As output variables: temperature of these hearths and concentration of residual carbon monoxide. To design an effective control strategy for the post-combustion subprocess, it is necessary to know the behavior of the variables in different situations and to obtain a process model. The objective of the work is to obtain a statistical model that represents the behavior of the post-combustion thread. 


\section{Materials and Methods}

\section{Description of The Reactor}

Herreshoff type furnaces [5], are composed of a metal cylinder, in an upright position, lined internally with chamotte bricks or high alumina, protected externally by a metal housing, agitation facilities, feed and discharge of ore and combustion chambers. They are formed internally by 17 hearths or hearths that are shaped like spherical vaults (Figure 1). The furnace has a central rotating shaft to which 68 arms are articulated, four for each hearth. Each arm has, depending on the hearth, eight to 12 vanes or inclined teeth. Depending on the area of the furnace, they will be withholding or sweeping and depending on the odd or even hearths, they will allow the discharge from one hearth to another in the form of zigzag. In peer hearths, the discharge is carried out through 30 holes located equidistant from the periphery, in odd hearths by a hole located in the center around the central axis. The combustion chambers are equipped with high pressure oil burners, which are located two for each hearth in: hearth six, hearth eight, hearth 10 , hearth 12; except hearths 14 and 15 that only have one camera. In each chamber: the oil distributor consists of a main valve, a filter to separate impurities, a solenoid valve, a thermometer, a manometer, a flow meter with bypass, a pressure regulator and the burner [6].

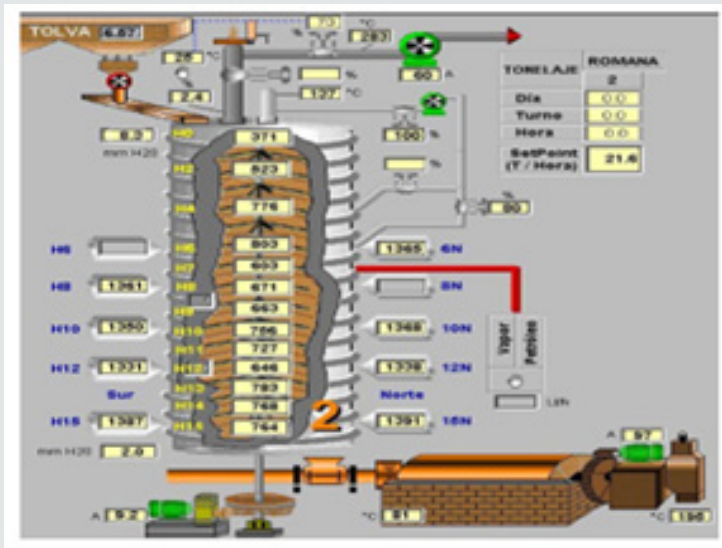

Figure 1: Schematic diagram of the reduction furnace seen from the SCADA (CITECT).

\section{Influence of Temperature in The Reduction Process}

Temperature is a fundamental parameter in pyrometallurgical processes, because it facilitates the weakening of the crystalline structures of the mineral and therefore the development of reduction reactions. During the operation, a certain prescribed profile must be maintained, increasing from the top to the bottom, in order to guarantee a gradual heating of the mineral. Special attention is paid to the temperature values of hearths four, 10 and 15. The temperature stability in hearth four is extremely important because of the influence it has on the temperature in the other furnace hearths. If there are temperature values below the norm, there is a displacement of the thermal zones of the furnace, which entails effects on the extraction of nickel and cobalt [7].

\section{Description of The Post-Combustion Installation}

The system consists basically of a centrifugal fan (Table 1) installed on the upper floor (ceiling) of the furnace, with hot air suction intake $\left(150\right.$ to $\left.200^{\circ} \mathrm{C}\right)$ from the chimney from the central axis and an air duct from the fan to hearths four and six, with flow regulation system through butterfly valves. The post-combustion air duct at the fan outlet, it has an internal diameter of $0.407 \mathrm{~m}$ and falls parallel to the furnace body to the four hearth, where it branches into two ducts of equal diameter, one goes to hearth four and the other to hearth six (Figure 1). Figure 2 shows the characteristics of the fan for the constant conditions in which it is operating. The fan curve intercepts the system characteristic curve at the operating point (A); for an approximate air flow that circulates before the fork of $6796 \mathrm{~m} 3 / \mathrm{h}$, with a pressure of 3 $\mathrm{kPa}$. Considering that the total air flow that is guaranteed before branching is constant and corresponds to a fixed duct air system; are presented in Table 2 airflow hearths four six after the split, according to the valve opening.

Table 1: Technical data of the post-combustion fan

\begin{tabular}{|c|c|}
\hline Fan type & PHD-685/100-100S \\
\hline Rotor speed & $233.4 \mathrm{rad} / \mathrm{s}$ \\
\hline Density & $855 \mathrm{~kg} / \mathrm{m}^{3}$ \\
\hline Engine & $11 \mathrm{~kW}$ \\
\hline Fan diameter & $685 \mathrm{~mm} \times$ Size $100 \%$ \\
\hline
\end{tabular}

Table 2: Equivalent air flow based on valve opening.

\begin{tabular}{|c|c|}
\hline Opening of the valve & Air flow \\
\hline to hearths four and six (\%) & to hearths four and six $\left(\mathrm{m}^{3} / \mathrm{h}\right)$ \\
\hline 10 & 679.6 \\
\hline 20 & 1359.2 \\
\hline 30 & 2038.8 \\
\hline 40 & 2718.4 \\
\hline 50 & 3398,0 \\
\hline 60 & 4077.6 \\
\hline 70 & 4757.2 \\
\hline 80 & 5436.8 \\
\hline 90 & 6616.4 \\
\hline 100 & 6796.0 \\
\hline
\end{tabular}




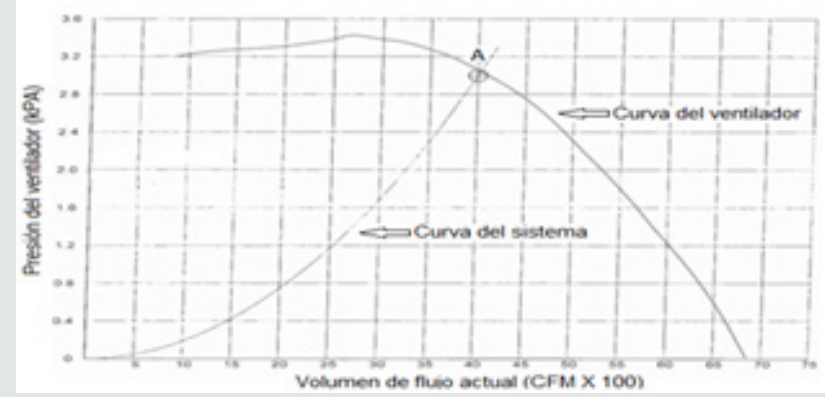

Figure 2: Characteristics of the afterburner fan

\section{Statistical Analysis of The Data}

The presentation of the data allows any researcher to easily interpret them. This presentation can be done in two ways:

a) Frequency Tables: It consists of grouping the data into classes or categories with their respective frequencies. It is applicable to any type of variable.

b) Graphics: example (Histogram). It is the representation of the data by rectangles that are based on a horizontal axis and their area proportional to the frequency of the class interval. They are used primarily for continuous variables.

\section{Regression Analysis}

Through a step-by-step regression analysis, the main variables that influence the process-dependent variables are determined, as well as the linear correlation coefficient.

\section{Results and Discussion}

As an auxiliary tool to select the variables to be used in the control, a statistical analysis was carried out based on a set of operating data, measured appropriately and continuously. The statistical analysis was carried out with the objective of determining the variables that have the greatest influence on the temperature behavior of hearths four and six of the furnace. For this analysis, five furnace operation data were taken during the months of May to July of a recent year and processed with Microsoft Excel and Statgraphics Plus 5.1 software. These data were obtained from the reports issued by the CITECT Supervisory System. Table 3 shows the average values represented by $(\mathrm{X})$ and the standard deviations by $(S)$ for each of the variables measured in the furnace, which are:

Table 3: Behavior of the furnace variables for three months of work.

\begin{tabular}{|c|c|c|c|c|c|c|}
\hline \multirow{3}{*}{ Variables } & \multicolumn{6}{|c|}{ Month } \\
\hline & \multicolumn{2}{|c|}{ May } & \multicolumn{2}{|c|}{ June } & \multicolumn{2}{|c|}{ July } \\
\hline & $\mathrm{X}$ & S & $\mathbf{X}$ & $S$ & $\mathbf{x}$ & S \\
\hline $\mathrm{ApH} 4$ & 46.2 & 27.07 & 35.22 & 22.6 & 46.87 & 22.36 \\
\hline ApH6 & 24.14 & 10.91 & 24.36 & 10.81 & 25.68 & 12.99 \\
\hline THO & 435.92 & 25.28 & 424.29 & 26.2 & 421.71 & 24.65 \\
\hline TH2 & 538.77 & 35.79 & 535.318 & 34.31 & 528.04 & 36.11 \\
\hline TH4 & 718.21 & 82.33 & 731.01 & 76.97 & 709,43 & 77.96 \\
\hline TH6 & 726.31 & 62.51 & 723.51 & 67.47 & 702.24 & 80.32 \\
\hline TH7 & 557.1 & 35.25 & 569.73 & 40.42 & 548.37 & 39.52 \\
\hline TH9 & 682.73 & 28.5 & 673,22 & 33.62 & 658.39 & 35.77 \\
\hline TH11 & 725.42 & 28.72 & 721.52 & 37.18 & 728.61 & 37.23 \\
\hline TH13 & 710.53 & 30.67 & 705.47 & 40.35 & 713.08 & 33.96 \\
\hline TH14 & 728.53 & 37.28 & 721.14 & 50.95 & 735.59 & 33.73 \\
\hline TH15 & 764.81 & 45.81 & 756.48 & 68.92 & 770.39 & 39.61 \\
\hline PHO & 100.85 & 31.98 & 74.75 & 21.48 & 65.43 & 28.35 \\
\hline PH16 & 22.37 & 24.63 & 17.27 & 24.33 & 17.07 & 25.02 \\
\hline TC6S & 1357.47 & 118.75 & 1338.48 & 170.03 & 1355.61 & 118.27 \\
\hline TC8N & 1356.82 & 116.82 & 1328.4 & 180.16 & 1346.16 & 135.09 \\
\hline TC8S & 1348.29 & 131.98 & 1328.24 & 183.11 & 1352.52 & 135.96 \\
\hline TC10N & 983.54 & 183.6 & 1101.14 & 208.34 & 1128.98 & 19189 \\
\hline TC10S & 860.59 & 57.34 & 867.01 & 115.01 & 839.86 & 89.27 \\
\hline TC12S & 1355.72 & 110.81 & 1312.23 & 232.58 & 1353.23 & 115.43 \\
\hline TC12N & 1357.21 & 132.89 & 1320.75 & 190.95 & 1351.29 & 145.93 \\
\hline TC15S & 1358.36 & 123.31 & 1280.77 & 320.61 & 1350.9 & 135.13 \\
\hline $\mathrm{CO}$ & 1.91 & 1.36 & 1.04 & 1.44 & 1.12 & 1.44 \\
\hline
\end{tabular}


1. ApH4, ApH6 [Opening of the air flow regulating valve to hearths four and six (\%)].

2. TH0, TH2, TH4, TH6, TH7, TH9, TH11, TH13, TH14, TH15 [Hearth temperature zero, two, four, six, seven, nine, 11, 14 and 15 respectively $\left.\left({ }^{\circ} \mathrm{C}\right)\right]$.

3. PH0, PH16 [Pressure in hearths zero and $16(\mathrm{~Pa})]$.

4. TC6S, TC8N, TC8S, TC10N, TC10S, TC12N, TC12S, TC15S [Temperature of combustion chambers, hearths six, eight, 12 and 15 , north and south side $\left.\left({ }^{\circ} \mathrm{C}\right)\right]$.

5. CO [Residual carbon monoxide concentration (\%)].

In the months indicated above, the post-combustion air flow meter was not installed, so that the openings of the air flow regulating valves to hearths four and six were taken, as proportional measures to the air flow.
The ore processed during this period was of very good characteristics, with a high iron content. A descriptive statistical analysis of the general trend of the thermal profile of hearths four and six during these three months of work, the results of which are presented in Table 4. For this case it is observed that the values of Kurtosis and the Asymmetry Coefficient allow us to state that the dependent variables (temperature of hearths four and six) behave like normal distributions. The frequency histograms for TH4 and TH6 are also presented during the three months of work in Figures 3-8. histogram. With the data for the month of May, a step-by-step regression analysis was carried out to determine the independent variables that most influence TH4 and TH6 (see equations 1 and 2).

1) $\mathrm{TH} 4=-166.9+0.3 \mathrm{TC} 8 \mathrm{~S}-0.5 \mathrm{TH} 0+0.13 \mathrm{TH} 13+1.4 \mathrm{TH} 2-$ $0.8 \mathrm{ApH} 4-0.1 \mathrm{TH} 6$

2) $\mathrm{TH} 6=171.6+0.3 \mathrm{TC} 6 \mathrm{~S}+0.8 \mathrm{TH} 13-1,1 \mathrm{TH} 14+0.7 \mathrm{TH} 15-$ $0.13 \mathrm{TH} 4-0.2 \mathrm{ApH} 4+0.6 \mathrm{ApH} 6+0.9 \mathrm{TH} 7-0.9 \mathrm{TH} 9$

Table 4: Summary of the descriptive statistical analysis of the sample for three months.

\begin{tabular}{|c|c|c|c|c|c|c|}
\hline \multirow{3}{*}{ Statistical functions } & \multicolumn{6}{|c|}{ Month } \\
\hline & \multicolumn{2}{|c|}{ May } & \multicolumn{2}{|c|}{ June } & \multicolumn{2}{|c|}{ July } \\
\hline & TH4 & TH6 & TH4 & TH6 & TH4 & TH6 \\
\hline Average & 718.2 & 726.3 & 731 & 723.5 & 709.4 & 702.2 \\
\hline Typical error & 0.6 & 0.4 & 0.5 & 0.5 & 0.5 & 0.5 \\
\hline Medium & 734.9 & 734.8 & 748.7 & 734.7 & 717.2 & 710.9 \\
\hline Fashion & 498.9 & 597.9 & 610.9 & 607.9 & 430.9 & 454.9 \\
\hline Standard deviation & 82.3 & 62.5 & 76.9 & 67,5 & 77.9 & 80.3 \\
\hline Sample variance & 6778.8 & 3907.9 & 5923.7 & 4552.7 & 6077 & 6450.9 \\
\hline Kurtosis & 2.1 & 1.4 & 1.9 & 2.9 & 1.9 & 2.2 \\
\hline Asymmetry coefficient & -1.2 & -0.6 & -1.1 & -1 & -0.9 & -0.7 \\
\hline Range & 593.1 & 582.1 & 690.9 & 624.1 & 580.7 & 706.7 \\
\hline Minimum & 319.9 & 473.4 & 418.3 & 425.5 & 352 & 291.8 \\
\hline Maximum & 912.9 & 1055.5 & 1109.1 & 1049.6 & 932.8 & 998.5 \\
\hline Confidence level (95.0\%) & 1.1 & 0.9 & 1 & 0.9 & 1 & 1 \\
\hline
\end{tabular}

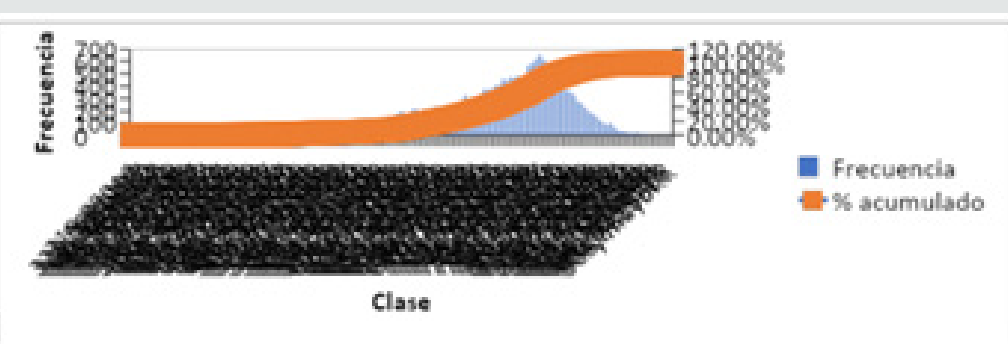

Figure 3: Characteristics of the post-combustion fan 


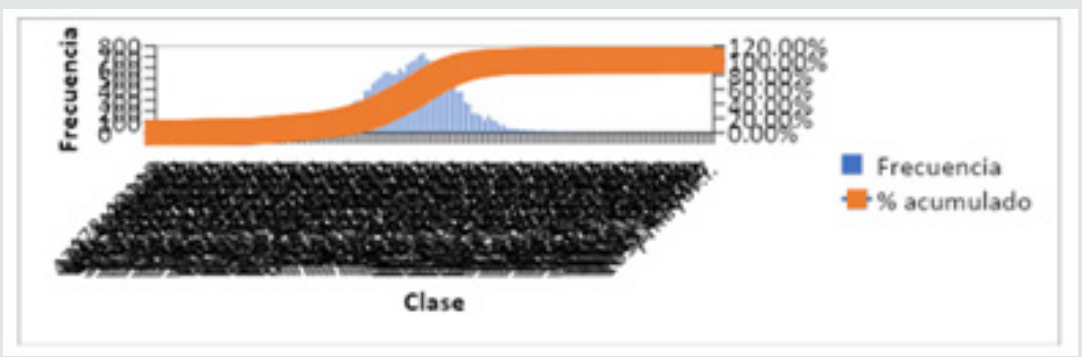

Figure 4: Hearth temperature histogram six (TH6). May

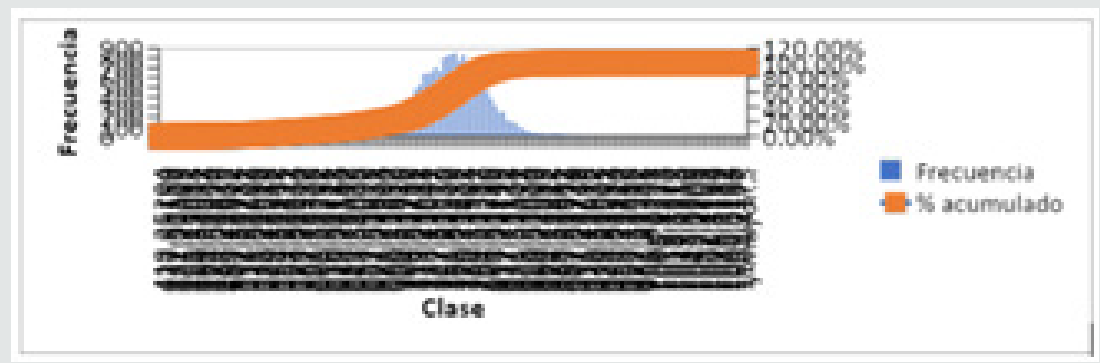

Figure 5: Hearth temperature histogram four (TH4). June

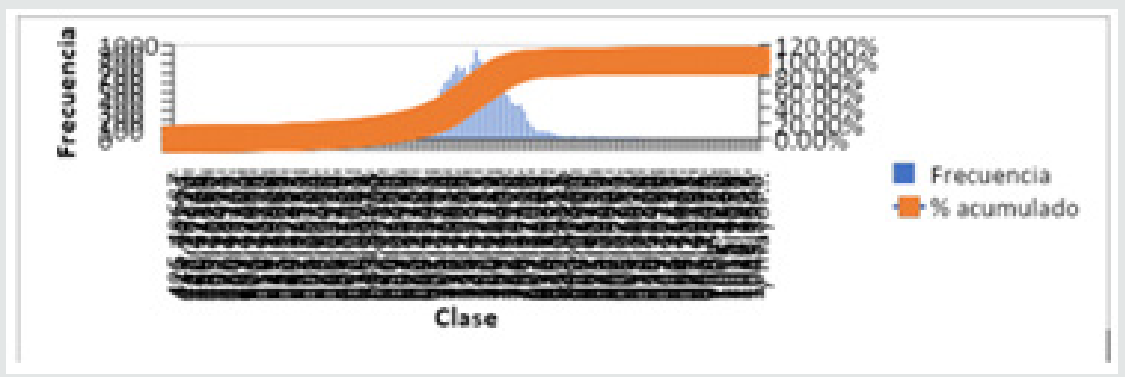

Figure 6: Hearth temperature histogram six (TH6). June

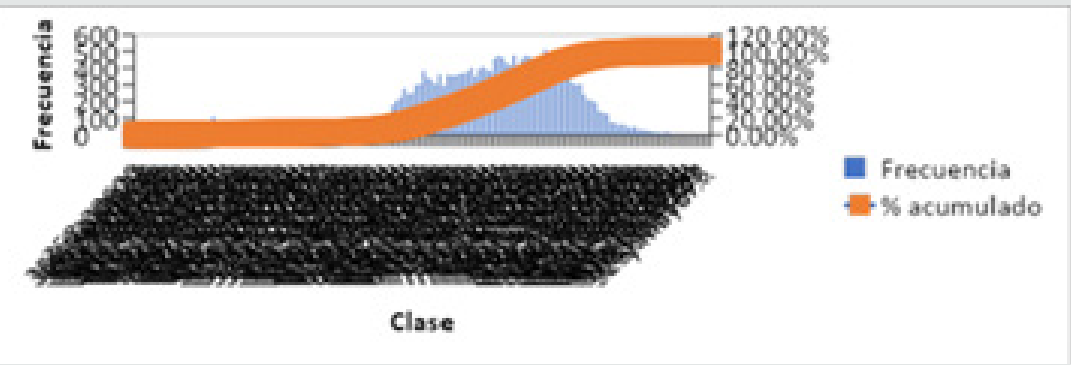

Figure 7: Hearth temperature histogram four (TH4). July

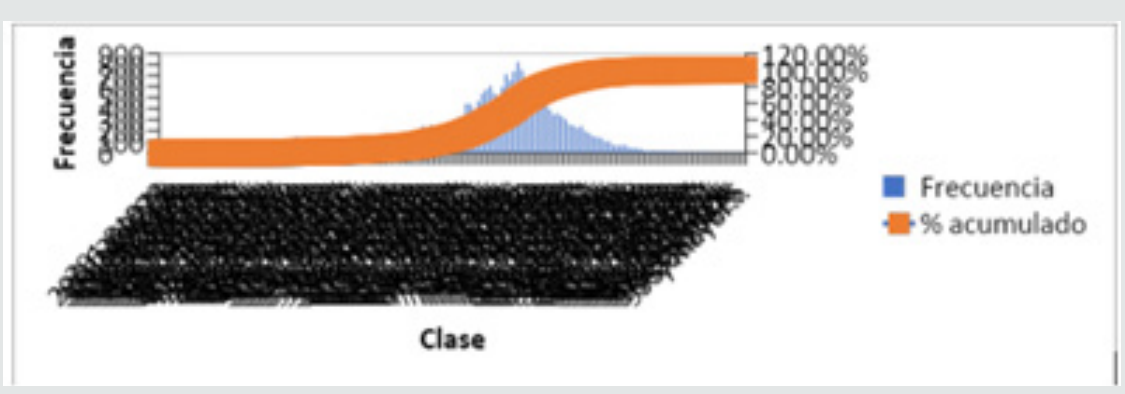

Figure 8: Hearth temperature histogram six (TH6). July 
In Table 5 , the statistic $\mathrm{R}^{2}$ indicates that model 1 explains 0.62 of the variability in hearth temperature four, while model 2 explains 0.42 of the variability in hearth temperature six. The statistic $\mathrm{R}^{2}$ adjusted, which is more convenient for comparing models with different numbers of independent variables, is 0.62 for TH4 and 0.42 for TH6. The standard error of the estimate shows the standard deviation of the residuals, which is 50.62 for TH4 and 47.35 for TH6. Tables $6 \& 7$ show the analysis of variance for the dependent variables TH4 and TH6. It is noted that the percentages are less than 0.01 , so there is a statistically significant relationship between the variables for a $99 \%$ confidence level.

Table 5: Summary of the regression analysis for TH4 and TH6.

\begin{tabular}{|c|c|c|}
\hline \multirow{2}{*}{ Regression statistics } & \multicolumn{2}{|c|}{ Variables } \\
\cline { 2 - 3 } & TH4 & TH6 \\
\hline Multiple correlation coefficient & 0.79 & 0.65 \\
\hline Determination coefficient $\mathrm{R}^{2}$ & 0.62 & 0.42 \\
\hline $\mathrm{R}^{2}$ adjusted & 0.62 & 0.42 \\
\hline Typical error & 50.62 & 47.35 \\
\hline
\end{tabular}

Table 6: Analysis of variance for hearth temperature four.

\begin{tabular}{|c|c|c|c|c|c|}
\hline Source & $\begin{array}{c}\text { Sum of } \\
\text { Squares }\end{array}$ & $\begin{array}{c}\text { Degrees } \\
\text { of Free- } \\
\text { dom }\end{array}$ & $\begin{array}{c}\text { Medium } \\
\text { Square }\end{array}$ & $\begin{array}{c}\text { Comp. } \\
\text { Var. }\end{array}$ & $\begin{array}{c}\text { Percent- } \\
\text { age }\end{array}$ \\
\hline Model & $\begin{array}{c}8,80424 \\
10^{7}\end{array}$ & 6 & $\begin{array}{c}1,46737 \\
10^{7}\end{array}$ & $\begin{array}{c}5 \\
727.11\end{array}$ & 0.0000 \\
\hline Waste & $\begin{array}{c}5,34722 \\
\cdot 10^{7}\end{array}$ & 20870 & 2562.15 & 231,765 & \\
\hline
\end{tabular}

Table 7: Analysis of variance for hearth temperature six.

\begin{tabular}{|c|c|c|c|c|c|}
\hline Source & $\begin{array}{c}\text { Sum of } \\
\text { Squares }\end{array}$ & $\begin{array}{c}\text { Degrees } \\
\text { of Free- } \\
\text { dom }\end{array}$ & $\begin{array}{c}\text { Medium } \\
\text { Square }\end{array}$ & $\begin{array}{c}\text { Comp. } \\
\text { Var. }\end{array}$ & $\begin{array}{c}\text { Per- } \\
\text { centage }\end{array}$ \\
\hline Model & $\begin{array}{c}3,47949 \\
\cdot 10^{7}\end{array}$ & 9 & $3,8661 \cdot 10^{6}$ & 1724.26 & 0.0000 \\
\hline Waste & $\begin{array}{c}4,67876 \cdot \\
10^{7}\end{array}$ & 20867 & 2242.18 & & \\
\hline
\end{tabular}

\section{Conclusion}

As a result of the statistical analysis, the influence of six variables can be seen for hearth temperature four and nine for hearth temperature six. The openings of the air flow regulating valves, which can be manipulated by a final action element, are highlighted. The multivariable nature of the thermal profile of hearths four and six was verified, with respect to the flow of air supplied to these hearths.

\section{References}

1. Castellanos J (1986) Development of oxidized nickel ores by the carbonate-ammonia scheme. Mining and Geology 4(2): 77-80.

2. Habashi F (1997) Handbook of Extractive Metallurgy (Vol. II) Weinheim, Germany, Wiley-VCH.

3. Miranda J, Chaviano R, Miranda JR (2002) New chemical-mineralogical interpretations of lateritic and serpentine ores, through the pyrometallurgical process, in carbonate-ammoniacal technology. Cuban Journal of Chemistry 14(2): 42-50.

4. Montero D (2012) Experimental identification of the post-combustion subprocess in a nickel reduction furnace. Moa, Cuba: ENERMOA.

5. Ramírez M (2001) Experimental identification of the post-combustion subprocess in a nickel reduction furnace. Mining and Geology 18(2): 6166.

6. Ramírez M (2002) Modeling of the afterburning process in a nickel reduction furnace. Metallurgy Magazine 38(2): 150-157.

7. Tavío G (1999) Optimization of nickel reduction in reduction furnaces equipped with PRIOR chambers. XVI Chemistry Conference. Santiago de Cuba.
(C) (1) This work is licensed under Creative

To Submit Your Article Click Here:

Submit Article

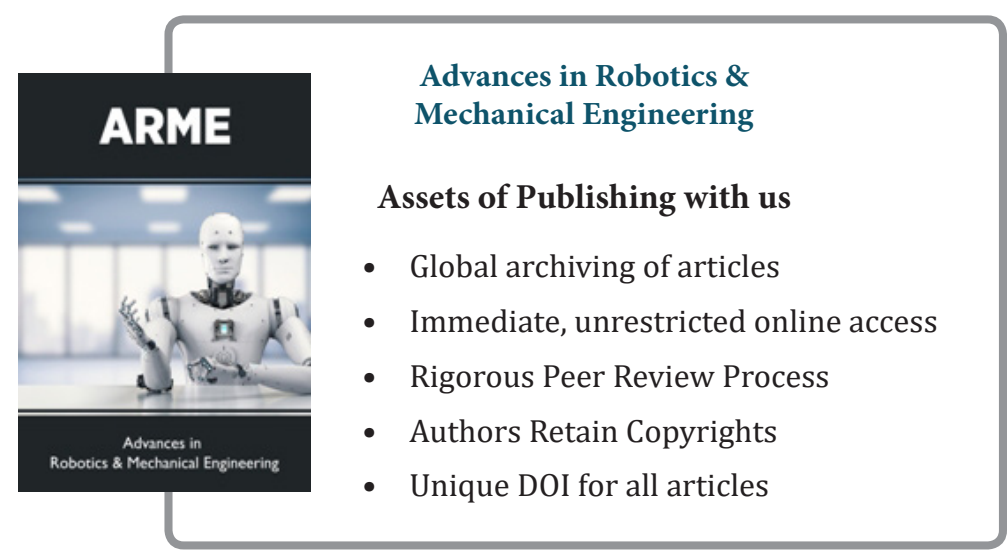

